Stefanidis, A., \& Strogilos, V., Kyriakidou, N. (2020). Work engagement of employees who are parents of children with disabilities: Empirical evidence from Singapore and the United Kingdom.

International Journal of Human Resource Management.

https://doi.org/10.1080/09585192.2020.1800783

\title{
Work Engagement of Employees Who Are Parents of Children with Disabilities: Empirical Evidence from Singapore and the United Kingdom
}

\begin{abstract}
Work engagement has attracted increased interest among human resource management scholars and practitioners. Within a family-work context, a population whose levels of work engagement has sparsely been previously studied has been that of employees who have children with special needs/disabilities (SND). These employees frequently face demanding responsibilities at home, a fact that may have implications in the workplace. Drawing on perceived family-work strain and organizational support literatures, we examine whether the disability severity of employees' children and the support provided by the supervisor may affect employees' levels of work engagement. Deriving data from two societies, those of Singapore and the United Kingdom (UK), the findings of this research may inform human resource management literature concerning the work engagement of employees who are parents of children with SND. Our two-society data collection rendered 430 usable questionnaires. Employees with children with SND in Singapore $(n=224)$ reported higher work engagement levels than employees in the UK $(n=206)$. Also, the research results confirmed that the relationship between child's disability severity and employee work engagement is moderated by the support provided by the supervisor. Setting the grounds for an international discussion about human resource management and family-support practices directed toward employees with children with SND, implications and recommendations for future research are offered.
\end{abstract}

Keywords: work engagement, supervisor's support, parents, disability, diversity, organizational support, Singapore, United Kingdom.

In recent years, employees' family-work issues have attracted increasing attention among researchers and practitioners. Despite this development, a population whose family-work lives have received limited consideration has been that of working parents of children with special needs/ disabilities (SND). As a result, we currently know little about the inclusion of these employees in the workplace (Li, Shaffer, \& Bagger, 2015; Stewart, 2013), as well as their work-related wellbeing (Breevaart \& Bakker, 2011). Caring responsibilities for a child with SND have been associated with negative consequences on the number of work hours, the opportunities for promotions, and the specific duties employees can take on (Buckner and Yeandle, 2012). For instance, according to the Working Families and Unum's (2018) survey, in the United Kingdom (UK), more than $75 \%$ of parents with children with SND turned down a promotion or accepted a demotion due to their caring responsibilities. Similarly, according to CONTACT (2018), when compared with employees with non-caregiving responsibilities, employees with children with SND are more likely to decline a promotion or be in low-paid and low-skilled jobs.

Hermanns and Mastel-Smith (2012) define caregiving as the process of helping individuals who are unable to care for themselves. This help may refer to supporting individuals' physical, mental, emotional and/ or social needs. Morris (2012) has raised several concerns about the ability 
of employed caregivers to balance family and work life, especially for parents of children with more severe disability types. Indeed, the caregiving of children with SND is related to the nature and the number of tasks that parents have to undertake as a result of the severity of their children's disability (Lambe, 2012). As such, low-functioning children with disabilities (e.g., low-functioning autism or severe intellectual disabilities) need more intensive care than high-functioning children (e.g., high functioning autism or mild intellectual disabilities). The severity of the child's disability is commonly indicated in the literature as a source of parental strain that has negative implications on both family and work issues (e.g., Warfield, 2005). Although researchers note that employees with children with SND experience challenges in their work, the impact of the disability severity on employed parents' work and home lives has received little attention (e.g., Brannan, et al., 2018).

Given that parents with children with SND constitute a working population that has increased family strain, it becomes evidently valuable to investigate these employees' levels of engagement toward their work. Although there is some literature that examines the work engagement of employees who are caregivers of elderly family members (e.g., Zacher \& Winter, 2011), the work engagement of employees who are parents of children with SND, as well as the impact of disability severity on their work engagement levels, still remain under-researched (Breevaart \& Bakker, 2011). Furthermore, although the social support available in the workplace has been reported to have positive outcomes on employees' levels of work engagement (e.g., Swanberg, McKechnie, Ojha \& James, 2011), the role of supervisor's support in increasing work engagement levels of employees with children with SND has been sporadically studied (e.g., Matthews et al., 2011). Considering that the support provided by supervisors has been suggested to mitigate the strain that employees with demanding eldercare responsibilities experience at home and, thus, to hold a buffering role in the relationship between eldercare strain and work engagement (Zacher \& Winter, 2011), the examination of these relationships among employees who experience increased parental strain as caregivers of children with SND is warranted.

Therefore, in this study, drawing on family-work strain (Hobfoll, 1989) and perceived organizational support (Eisenberger et al., 1986; Eisenberger et al., 2002; Thomas \& Ganster, 1995) literatures, we investigate employee work engagement considering the family-work strain derived from the disability severity levels of employees' children in relation to the support that employees receive from their supervisor. Researching factors associated with the work engagement levels of this working population has the potential to contribute to the diversity as well as the human resource management literatures. Specifically, accounting for workforce heterogeneity, this study sets the goal of measuring the job attitudes of employees who are parents of children with SND, while considering both the organizational and family contexts, in order to enhance our theoretical knowledge about specific factors that contribute to work engagement levels of these caregivers. Recognizing that childcare responsibilities may vary depending on children's disability severity levels (Rosenzweig, Brennan \& Ogilvie, 2002), this research endeavors to empirically examine relationships refining existing theoretical underpinnings of work engagement, simultaneously strengthening the predictive power of prior research models.

In this context, considering both the professional and family lives of employees with children with SND, the present study focuses on the societies of Singapore and the UK. The number of caregivers with children with SND in the two societies has been growing, as the reported number of children with SND both in England (from 14.4\% in 2017 to 14.6\% in 2018) (DfE, 2018) and in Singapore (from 2050 in 2010 to 4400 children with developmental disabilities in 2014) (NCSS, 2014) is increasing. At the same time, the two societies, which are economically developed, embrace the inclusion of diverse populations (e.g., employees from multicultural backgrounds), 
and, therefore, research outcomes may generate valuable insight so that organizations and policymakers may introduce workplace practices more efficiently targeted toward the diverse population of employees with children with SND in these specific societal contexts.

\section{Literature review and hypotheses development The research context}

Employed caregivers in the UK and in Singapore are supported differently. On the one hand, the UK has introduced legislation to allow caregivers to maintain their work through flexible work schedules, parental leaves and other statutory rights regarding paid leave (Children and Families Act, 2014). Employees have the right to request flexible employment after they have worked for an employer for 26 weeks (Working Families, 2019). Furthermore, parents of children with SND may be entitled to income-based state support or other indirect benefits for care and medical support (Buckner \& Yeandle, 2006) and a number of respite care options. On the other hand, Singapore has not introduced specific legislative initiatives to accommodate the needs of employed caregivers at work. Yet, the government has recently published its intention to further support disability caregivers based mainly on home-based arrangements, including the improvement of home-care services, the funding of new service models for children with disabilities, and the introduction of training programs for caregivers) (NCSS, 2016). In a recent survey, the Ministry of Manpower (2016) indicated that most companies in Singapore prefer to offer ad-hoc flexible work arrangements and other work-life initiatives to help employees cope with personal and family commitments on a case by case basis (76.4\%) over instituting formal processes (47\%), as the former requires minimal adjustments to work. Moreover, it is worth mentioning that, contrary to the UK, foreign domestic helpers are highly available, affordable and socially acceptable in Singapore, and they help alleviate family strain for employees with children with disabilities. Recently, the Singaporean government has introduced levy concessions and grants for foreign domestic helpers and home-based care services for families with children with SND (NCSS, 2016).

Despite the series of welcoming political initiatives and outstanding forward motions in both employment law (i.e., Children and Families Act, 2014; European Commission, 2010; NCSS, 2016) and employer best practices, unfavorable conditions surrounding flexible and family-friendly work practices in both societies persist. As Fetton and Mearns (2012) note, in the UK, parents of children with SND face significant challenges that are often overlooked by employers, service suppliers, and policy makers. There are still many legislative gaps that contribute negatively to the employment of working parents of children with SND, including inflexibility in accessing healthcare, affordable childcare, education services, work benefits, opportunities for part-time work and flexible work arrangements, and services available to parents who wish to return to employment (BIC 2011b; Fetton \& Mearns, 2015). In Singapore, a Lien Foundation (2016) survey with over 1000 participants concluded that even though there is ideological support for the inclusion of children with SND and their families, the country has yet to take steps to enhance social support. In addition, the 2012-2016 Enabling Masterplan (NCSS, 2012) indicated that the burden of tending to children with SND falls mostly on mothers, with two in five families having a parent who quits work. According to the new 2017-2020 Enabling Masterplan (NCSS, 2016), Singaporean parents of children with SND who are employed full-time face challenges in carrying out their caregiving functions. Thus, this masterplan proposes additional support to parents, such as the options to switch to part-time employment, to work flexible hours or to choose childcare leave, depicting the lack of institutionalized policy initiatives regarding support that should be provided to employees with children with SND.

\section{Work engagement}


An important consideration regarding employed parents of children with SND is their interest in their work (Warfield, 2001). Employee work engagement is described by 'heavy work investment' in terms of time and effort, and levels of engagement are frequently associated with employee performance. Literature highlights several variables that may influence work engagement, including financial rewards and performance feedback (Farndale \& Murrer, 2015), and supervisor's support (Swanberg et al., 2011). According to Bakker and Demerouti (2008), physical, social or organizational aspects of the job "play an intrinsic motivational role because they foster employees' growth, learning and development, or an extrinsic motivational role because they are instrumental in achieving work goals" (p. 211). Demerouti et al. (2001) and Bakker and Demerouti (2007) indicate that factors such as social support, organizational justice and organizational climate relate positively to work engagement. However, as Schaufeli (2018) explains, work engagement levels of employees from different societies tend to vary, and, more efforts to report variations in levels of work engagement internationally are necessary.

In this context, the present research sought to compare work engagement amongst employees in Singapore and the UK. As Flade (2003) indicates, the cost of disengaged employees in the UK ranges between $£ 37.2$ billion to $£ 38.9$ billion per year, whereas, the cost of disengaged employees in Singapore is between $£ 4.9$ billion and $£ 6.7$ billion per year. To the authors' knowledge, there have been no empirical studies that compare work engagement between the two societies. However, a small number of single-society studies in the UK and Singapore have identified associations between specific variables and work engagement levels. In the UK, for example, Lai, Saridakis and Blackburn (2015) found that higher levels of work engagement are met more frequently in large enterprises than in medium-sized ones. Alfes et al.'s (2013) study in UK service-sector organizations, revealed that line managers' perceived behavior and human resource management practices positively affect employee engagement, which in turn is positively linked to individual performance. Denton, Newton \& Bower's research (2008) reported that UK dentists who had postgraduate certificates and worked in large teams displayed higher levels of work engagement. Accordingly, a recent study by Yang, Meredith and Kahn (2014) focusing on mental health services found that, in Singapore, younger, less experienced and lower income employees have higher levels of stress and burnout, two conditions that, in the literature, have been negatively related with work engagement.

Although the factorial validity of the Schaufeli et al.'s (2006) work engagement scale has been tested internationally, only a few articles, which are largely limited to Western societies, have analyzed cross-societal differences in work engagement levels among employees (Shimazu et al., 2010). Emphasizing the need for inclusion of non-Western samples in cross-societal comparisons, Brough et al. (2013) identified significantly higher levels of work engagement among employees in Australia compared to engagement levels among Chinese employees (Brough et al., 2013). Similarly, Deci et al. (2001) reported that US employees displayed higher levels of work engagement than their Bulgarian counterparts. Such cross-societal variations have been further strengthened by the identification of significant differences in the levels of work engagement among employees of 35 European societies (Schaufeli, 2018). Schaufeli (2018) suggests that variations in the governance, economic and cultural contexts may account for differences in the levels of work engagement among employees from diverse societies. Assessing the indicators suggested by Schaufeli (2018), the two studied societies display significant differences considering: control of corruption scores (Singapore: 2.07, UK: 1.88) (World Bank, 2017), voice and accountability scores (Singapore: -0.28, UK: 1.24) (World Bank, 2017) and democracy scores (Singapore: 6.32, UK: 8.53) (Economist Intelligence Unit, 2017). Moreover, Singapore and the UK display variations with 
regard to economic variables, such as GDP per capita (Singapore: $\$ 90,500$, UK: $\$ 43,600$ ) (CIA, 2017) and GDP per worker (Singapore: \$151,522, UK: \$81,370) (International Labour Organization Department of Statistics, 2019). In addition, the two societies have traditionally been culturally diverse. In the GLOBE study of 62 societies, England is grouped under the Anglo cluster, whereas Singapore is grouped under the Confucian Asia cluster of societies (House et al., 2004). Given the significant cultural differences between the two studied societies (Hofstede, 2017), e.g., in terms of individualism (Singapore score: 20, UK score: 89), power distance (Singapore score: 74, UK score: 35) and uncertainty avoidance (Singapore score: 8, UK score: 35) dimensions, research points to the direction that employee attitudes toward work engagement in the two societies would differ significantly. One could expect that, the differences derived from institutional, economic and cultural variations among societies (Schaufeli 2018) would become more evident when comparing societies that provide formal support in the workplace for employees with children with SND with societies that do not. As described in the introduction, the UK officially supports employed caregivers through specific arrangements only in the workplace (Children and Families Act, 2014). However, in Singapore, beyond the ad-hoc flexible work arrangements by $76.4 \%$ of employers (Ministry of Manpower, 2016), the government has also introduced several family-based support arrangements (NCSS, 2016). In addition, in Singapore, live-in domestic helpers are affordable and socially acceptable (Poon, 2017), and their support can alleviate significantly the strain deriving from increased childcare responsibilities associated with disability. This type of help at home is not a resource that employees in the UK can easily access. Therefore, in line with evidence from the extant literature regarding the economic, institutional, and cultural contexts, as well as the fact that, in addition to work-based support, Singaporean employees with children with SND have increased access to family-based support, we formulate the following hypothesis regarding expected variations in work engagement levels of employees in the two societies:

Hypothesis 1: Employees who are parents of children with disabilities in Singapore will display significantly higher levels of work engagement than employees who are parents of children with disabilities in the $U K$.

\section{Disability severity}

Parents of children with SND, especially of children with severe disabilities (Wright, Crettenden \& Skinner, 2016), are commonly referred to in the literature as a group of parents with high caregiving responsibilities in comparison to parents with typically developing children, and their demanding responsibilities tend to create conflict between family and work. For example, in their comparison between employed mothers of typically developing children and mothers of children with special health care needs, Dillon-Wallace, Donagh and Fordham (2016) found that the latter reported higher levels of strain and fewer gains regarding work-life balance. Brennan and Brannan (2004) reported that higher strain levels of caregivers of children with emotional and behavioral difficulties were associated with lower levels of employment participation. Similarly, Warfield (2001) found that mothers of children with developmental disabilities who experienced increased parenting stress due to their child's disability, rated their jobs as less interesting. Matthews et al. (2011) studied the increased family demands that derived from having a child with autism spectrum disorder and reported that parents' strain-based family-to-work conflict impacted negatively their engagement at work, as this was reflected in reduced numbers of work hours and in lower performance. Notably, for employees who were also parents of children with severe multiple disabilities (Rosenzweig et al., 2002), increased care demands impacted negatively their work lives and performance. 
Hobfoll's (1989) conservation of resources perspective explains that increased conflict and stress may consume employees' accumulated resources, adversely impacting their well-being. Drawing on a family-work strain perspective (ten Brummelhuis \& Bakker, 2012), several investigators have associated contextual family demands with adverse job consequences, such as lower job satisfaction, lower job performance, higher levels of stress, and an increased desire to leave work and seek employment elsewhere (e.g., Behson, 2002; Ford et al., 2007). In general, "conflict caused by demands from the family domain that limits one's abilities to meet responsibilities at work" (Bagger \& Li, 2012, p. 474) is considered a form of inter-role conflict in which time devoted to the family and strain created by the family (e.g., care for dependent family members) interfere with performing work-related responsibilities (Netemeyer, Boles \& McMurrian, 1996). Having childcare responsibilities may increase family-work conflict (FWC), and researchers have examined employees' family commitments deriving from factors, such as the number of children at home (Grandey \& Cropanzano, 1999; Netemeyer et al., 1996), economic hardship (Schieman \& Young, 2011), the degree of responsibility the caregivers have (i.e., primary, secondary or equal) (Frye \& Breaugh, 2004), the low independence levels of children, spouses or parents (Bainbridge, \& Broady, 2017) or other increased responsibilities (e.g., provide care to sick children or children with SND) (Buckner \& Yeandle, 2006; Kulik, Cregan, \& Bainbridge, 2013).

Prior studies have observed a relationship between the severity of child's disability and various work variables. For example, a positive association between child's disability severity and work absenteeism among parents with children with emotional and behavioral disorders was reported by Brennan and Brannan (2005). Wright et al. (2016) reported a similar negative association between Australian fathers with children with severe disabilities and their job opportunities and career progression. Warfield (2005) identified significantly lower stress levels among mothers who have children with mild behavioral problems, compared with those who had children with severe behavioral problems. Similarly, Booth and Kelly (1998) found that the impact on mothers' work plans was greater for those mothers who had children with severe disabilities and chronic health problems. In view of these research results, we infer that:

Hypothesis 2: Higher levels of child's disability severity will have a negative impact on work engagement levels of employees who are parents of children with disabilities.

\section{Supervisor's support}

Support provided by the supervisor has been found to influence employees' psychological wellbeing (Saks, 2006). Rousseau and Aube (2010) state that supervisor support includes caring about subordinates, valuing their contributions, and helping them on work-related issues and skill development. Zhang et al.'s (2016) research among Chinese employees has proposed that subordinates actively seek to develop guanxi with their supervisors to receive support pertaining to their personal lives and family issues. Supervisor's support can be either instrumental or emotional. The former encompasses the provision of knowledge or advice, whereas the latter involves providing care and understanding or listening sympathetically to subordinates (Swanson \& Power, 2001). Supervisor's support eventually helps employees develop an emotional attachment and sustain their functioning in their employing organization (Rousseau \& Aube, 2010).

Perceived organizational support literature indicates that employees tend to perceive their supervisors as organizational agents, who direct and evaluate subordinates' performance, and, therefore, they directly associate supervisors' support with perceived organizational support (Eisenberger et al., 2002). Pan and Yeh (2012), in their study of 637 Taiwanese employees, found that employees' perceptions toward their supervisors influence their general perceptions toward 
their organizations. The authors assert that employees assess their organization as supportive, or not, depending on the signals they receive from the entire work environment, and that supervisors represent a source of exceptionally important signals. In general, perceived organizational support literature holds that support provided in the workplace may beneficially influence employee-related outcomes (Eisenberger et al., 1986).

The important role that supervisors' support plays for several workplace variables has been highlighted in various studies (e.g., Kossek et al., 2011; Zhang \& Liao, 2015). Although certain studies have not identified a significant relationship between supervisor's support and work engagement (Karatepe \& Olugbade, 2009; Saks, 2006), an increasing stream of empirical research has shown that supervisor's support is positively associated with work engagement. For example, Bakker et al. (2007) found that supervisor's support was an important job resource that boosted Finnish teachers' work engagement and helped them cope with demanding interactions with students. In a large US retail setting that included multiple age groups, James, McKechnie, and Swanberg (2011) indicated supervisor's support as one of the main quality factors in the engagement of employees. A similar positive association between supervisor's support and work engagement has been identified among US employees holding hourly retail jobs (Swanberg et al., 2011) as well as among Australian nurses (Holland, Cooper, \& Sheehan, 2016). In line with the above studies, Qing and Zhou (2017), in their two-wave survey among Chinese employees, found that, over time, family-supportive supervisor behaviors may positively predict work engagement, a finding that was also replicated in Rofcanin, Las Heras and Bakker's (2017) study, in which familysupportive supervisor behavior influenced subordinates' performance through work engagement. Li et al. (2014) also observed that social support has a positive effect on work engagement.

Indeed, in their literature review regarding employed parents with children with disabilities, Brown and Clark (2017) documented that the support provided by the supervisor was among the variables that have an impact on balancing family and work strain, a fact that can be associated with levels of employees' engagement in their work. Also, in Matthews's et al. (2011) qualitative examination with employed parents of children with autism spectrum disorder, participants acknowledged that they desired socio-emotional support from their supervisors, such as better understanding of their increased strain and schedule flexibility, and other accommodations that would allow them to disengage from family-life concerns while at work. Analogous findings were reported in Lewis, Kagan and Heaton's (2000) interview study on disability caregivers, in which parents who had supportive supervisors were more committed and loyal. Consequently, we infer that supervisor's support toward employees who are parents of children with disabilities may lead to increased levels of work engagement. We, thus, offer the following hypothesis:

Hypothesis 3: Higher levels of supervisor's support will have a positive impact on levels of work engagement of employees who are parents of children with disabilities.

\section{The moderating role of supervisor's support}

Less-requiring caregiving commitments and family-friendly work strategies have been found to alleviate family strain (Li, Shaffer \& Bagger, 2015; Stewart, 2013). Combining "family-strain" with "perceived organizational support" perspectives makes evident that increased family-related commitments may consume employee resources, such as time or energy, eradicating the positive results that workplace support may have on employees' engagement toward their work. As Parish and Cloud (2006) indicate, for employees with children with SND, increased caregiving strain can be constant, it can be cyclical or irregular, and it may evoke long periods of time away from work. Parents of children with disabilities frequently find themselves juggling multiple roles. 
In particular, it appears that highly demanding family and work commitments are associated with increased levels of stress, especially for those employees who perceive caregiving as a source of stress. According to Greenhaus \& Beutell (1985), this stress is derived from the great amount of time and energy required by caregiving demands. As a result, caregivers tend to experience lower levels of work commitment and work engagement (Greenhaus \& Beutell, 1985), or even social isolation and personal frustration (Bittman, Hill \& Thomson, 2007). Undesirable effects of increased family strain may be attenuated by job resources, such as perceived organizational support (Zacher \& Winter, 2011). In a study among working parents of children with behavioral problems, Breevaart and Bakker (2011) found that social support can moderate the relationship between child behavioral problems and family self-conflict. The authors argued that social support can buffer the negative effects of raising a child with behavioral problems on parental well-being.

Research demonstrates that employees who care for dependent family members experience high levels of career-personal life conflict, but strain's impact on employee well-being (e.g. job satisfaction or work engagement) is attenuated when they receive support at the workplace (Kossek, Lewis, \& Hammer, 2010; Lee, Walker, \& Shoup, 2001). To this end, a research study conducted by Stewart (2013) concluded that employees who are parents of children with SND experience high barriers in finding support at work and work-family conflict was negatively correlated with several support variables at work such as supervisor and co-workers support. The author also noted a significant negative relationship between FWC and supervisor's support, a finding that has been corroborated by other researchers (e.g., Mansour \& Tremblay, 2016). Drawing on evidence regarding supervisor's support and work engagement (e.g., ten Brummelhuis et al., 2014), family strain and work engagement (e.g., Qing \& Zhou, 2017), and family strain and supervisor's support (e.g., Stewart, 2013), we expect that supervisor's support would strengthen or weaken the relationship between strain derived from the disability severity of the employees' child and employees' levels of work engagement. Indeed, Zacher and Winter (2011) verified a relationship between perceived organizational support, strain deriving from employees' caregiving responsibilities at home, and work engagement. Their findings indicated a moderating relationship, showing that, when strain from caregiving is high, organizational support, e.g., supervisor support, is particularly beneficial for employee levels of work engagement. Therefore, we would expect that the impact of family strain, derived from the child's disability severity, on employee work engagement would be attenuated by the increased levels of supervisor support. We, thus, offer the following hypothesis:

Hypothesis 4: Supervisor's support will moderate the relationship between child's disability severity and work engagement of employees who are parents of children with disabilities.

\section{Method}

To identify the attitudes of employees with children with SND, a survey research in the form of a self-administered questionnaire was designed based on evidence from the existing literature regarding work engagement, supervisor's support and family-work conflict.

\section{Participants and Data Collection}

We collected data from parents (men or women) of children with SND, who were full-time or parttime employees within diverse organizational settings in Singapore and the UK. Participants were parents of children with different types of disabilities, including autism, intellectual disability, and sensory and physical disabilities.

We approached parents through special education and inclusive education institutions in the two societies. As a precondition for participation, parents stated that they were employed in a public 
or private organization during the period of the study. Anonymity and confidentiality were assured. We consider the sampling approach we followed a unique strength of our data collection method, since we avoided approaching employees within their workplace. The sensitivity of the 'special needs and disabilities' topic may be a reason for participants to be reluctant toward presenting an unbiased reality regarding their work environment, especially in more collectivistic cultures, such that of Singapore, where 'losing face' may be an essential concern of the employee (Singelis et al., 1995). A total of 224 (response rate $=28 \%$ ) and 206 (response rate $=25.75 \%$ ) usable responses were collected from Singapore and the UK respectively.

In Singapore, the participants' average age was 44.08 years (S.D. $=7.43) .57 \%$ of the participants were female. $70 \%$ of the respondents worked in the private sector, while $30 \%$ worked in the public sector. The participants' average work experience was 19.43 years (S.D. $=8.46$ ). $68.8 \%$ of the respondents had completed pre-university education, while $31.2 \%$ held a university degree. Indicative industries of employment of the participants included banking, finance, hospitality, logistics, education, media, and healthcare. $87.9 \%$ of the respondents shared parenthood with a partner. $11.2 \%$ had more than one child with SND in their family.

In the United Kingdom, the respondents' average age was 41.76 years (S.D. $=4.34$ ). $71 \%$ of the participants were male. $41 \%$ of the respondents worked in the private sector, while $59 \%$ worked in the public sector. The average work experience in our sample was 16.34 years (S.D. $=4.01)$. $31.1 \%$ of the respondents had completed high school education, 9.7\% held a two-year higher education degree, while $39.3 \%$ held a three- or four-year university degree. Some of the industries of employment of the participants included accounting, finance, education and healthcare. $63.6 \%$ of the respondents shared parenthood with a partner, $23.3 \%$ were divorced, $8.7 \%$ were single and $4.4 \%$ were widowed. $32 \%$ had more than one child with disabilities in their family.

The two samples were comparable in terms of age, education, work experience and employment sectors, whereas they were rather different in terms of shared parenthood.

\section{Measures}

In the compiled survey questionnaire, we included several constructs measuring employees' job attitudes and work-family demographic information. The employed variables' measures are described below.

Work Engagement. We adopted the Schaufeli et al.'s (2006) nine-item scale, which is a shortened version of the seventeen-item Utrecht Work Engagement Scale (UWES) developed by Schaufeli et al. in 2002. The Work Engagement items were assessed on a 7-point Likert scale ranging from 1, which corresponded to "Never," to 7, which corresponded to "Always" or "Every day." We first assessed the unidimensionality of the construct employing exploratory factor analysis (EFA). We hypothesized that the construct had a single-factor structure, following the recommendations of past researchers who observe that in multidimensional structures the interrelations among the acquired latent variables of covariance structure models are very high (Schaufeli et al., 2002; Schaufeli et al., 2006). The EFA rendered a one-factor solution that accounted for $65.03 \%$ of the total variance. We further validated the factor structure of the items performing confirmatory factor analysis (CFA) in MPlus (Muthén \& Muthén, 2017). A single-factor structure yielded a good fit to the data. Goodness-of-fit statistics $\left(\chi^{2} 2, \mathrm{~N}=430=4.03, \mathrm{p}=.13\right.$; $\mathrm{CFI}=.99 ; \mathrm{TLI}=.99 ; \mathrm{RMSEA}=.05 ; 90 \% \mathrm{CI}=$ $.00, .41)$ were evaluated and deemed to provide a good unidimensional fit (Cheung \& Rensvold, 2002; Hu \& Bentler 1999). The Cronbach's Alpha for this scale was .90, indicating high internal consistency in line with previous studies in which Cronbach's alpha ranged from .85 to .92 . The included items are: "I am enthusiastic about my job", "My job inspires me", "When I get up in the morning, I feel like going to work" and "I am proud of the work that I do". 
Disability Severity. Employees with children with disabilities indicated the level of their child's disability severity. We used a binary variable, where 0 represented low-functioning disability types (i.e., high levels of disability severity), whereas 1 represented high-functioning disability types (i.e., low levels of disability severity). Employees were asked to indicate their child's functioning, depending on different conditions, such as intellectual disability, physical, mental or sensory disability, or other health issues. According to World Health Organization (2001), this classification describes efficiently the complex interaction among the individual, the environment, and the disease or condition.

Supervisor's Support. Supervisor's Support to the participants was assessed employing the Thomas and Ganster's (1995) 9-item Supervisor Support Scale. For three of the scale items we substituted the word 'family' with the word 'parental' (responsibilities). The examined items referred to the frequency with which the participants' supervisor engaged in specific supportive behaviors in the past two months. Employees were asked to respond considering their roles as parents of children with disabilities/ special needs. A five-point Likert-type scale was used, where the responses ranged from $1=$ never to $5=$ very often. Exploratory and confirmatory factor analyses to validate the structure of the factor were performed. The single-factor structure presented a good fit $\left(\chi^{2} 2, \mathrm{~N}=430=\right.$ 9.66, $\mathrm{p}=.01 ; \mathrm{CFI}=.99 ; \mathrm{TLI}=.96 ; \mathrm{RMSEA}=.09 ; 90 \% \mathrm{CI}=.04, .16)$. The Cronbach's Alpha reliability coefficient of the scale was .83. The included items were: "My supervisor juggles tasks or duties to accommodate my parental responsibilities", "My supervisor shares ideas or advice", "My supervisor helps me to figure out how to solve a problem" and "My supervisor is understanding or sympathetic".

Control Variables. Participants were asked to report several demographic characteristics, such as industry of employment, education, work experience, number of children, and number of children with disabilities. Seven of these variables served as control variables. Besides controlling for gender, age, education and hierarchical rank, based on evidence from the extant literature, we also controlled for weekly workload (e.g., Swanberg et al., 2011; ten Brummelhuis et al., 2014), shared parenthood (e.g., Allen, 2001; Neal \& Hammer, 2009; Berber Pas, Eisinga, \& Doorewaard, 2016; White, Hill, McGovern, Mills, \& Smeaton, 2003) and number of children (e.g., Breevaart \& Bakker, 2011). Hierarchical rank within the organization was measured with the use of a ten-point scale (10=the highest rank, $1=$ the lowest rank) (Stefanidis et al., 2013). Weekly workload was measured in hours per week. Shared parenthood reflected whether employees lived with a partner at home (binary variable).

\section{Reliability and validity}

Reliability and validity were thoroughly considered during design, data collection and analysis stages of the research. Hence, several successive precautionary steps were adopted (Podsakoff et al., 2003). Specifically, we controlled for the development of response patterns, reversing a number of anchor scales in the questionnaire. To ensure the validity of the research instrument, a pilot-study with the participation of 20 employees in each society was conducted. The results of the pilot stage were used to further confirm face validity, clarity and relevance of the items, while comments made by the participating employees were addressed.

In addition to pretesting the consistency of the pilot questionnaire, we assessed the employed scales' internal reliability with Cronbach's Alpha index. Also, since in both Singapore and the UK participants' attitudes were measured employing self-reported constructs, we acknowledged potential common method bias issues and we employed several precautionary strategies. First, we adopted a procedural remedy for common method bias, by including in the questionnaire employee attitudes constructs related to their work, as well as family and children's 
school-lives, thus giving the participants the impression that the measurement of the predictor variables was not related to the measurement of the criterion variable (Podsakoff et al., 2003).

Second, we employed the Harman single-factor test (Podsakoff \& Organ, 1986). We did not observe any unusual variations in the collected responses. We first run an EFA with the included items forced to load on a single factor and we observed that the deriving single factor accounted for only $26.54 \%$ of the total variance. We also carefully examined the correlations matrix and confirmed the presence of a balanced mix of both significant and nonsignificant relationships among the included variables, with many correlations being close to zero.

In addition, we performed a CFA in Mplus (Muthén \& Muthén, 2017), including the two latent variables. The measurement model displayed an acceptable fit $\left(\chi^{2} 28, \mathrm{~N}=430=53.92, \mathrm{p}<0.01\right.$; $\mathrm{CFI}=.981 ; \mathrm{TLI}=.973 ; \mathrm{RMSEA}=.06 ; 90 \% \mathrm{CI}=.04, .08)(\mathrm{Hu}$ and Bentler, 1999). As a second step, we performed a CFA, allowing the measured variables to load on a single general factor. The deriving model displayed very poor fit $\left(\chi^{2} 20, \mathrm{~N}=430=623.49, \mathrm{p}=0.00 ; \mathrm{CFI}=.658 ; \mathrm{TLI}=.521\right.$; $\mathrm{RMSEA}=.27 ; 90 \% \mathrm{CI}=.25, .28)$. We, subsequently, concluded that there was not a single factor accounting for the majority of the covariance in the measured variables and we regarded the common method variance risks associated with this study as rather limited. As an additional step, we employed the unmeasured latent method construct technique, which involves adding a first-order method factor whose only measures are the indicators of the measurement model's factors that share a common method (Conway \& Lance, 2010; Podsakoff et al., 2012). The fit of the measurement model that also included the unmeasured latent factor $\left(\chi^{2} 28, \mathrm{~N}=430=53.84, \mathrm{p}<0.01\right.$; $\mathrm{CFI}=.980 ; \mathrm{TLI}=.971 ; \mathrm{RMSEA}=.06 ; 90 \% \mathrm{CI}=.04, .08)$ led us to conclude that common method variance issues in our research are rather limited.

We further assessed the psychometric properties of the measurement model, following Fornell and Larcker's (1981) recommendations regarding convergent validity and discriminant validity of the employed constructs. The calculated composite reliabilities (CR) of work engagement and supervisor's support scales were .90 and .83 , respectively. Accordingly, the average variances extracted (AVE) for the two factors were greater than .50 (Bagozzi \& Yi, 1988) and the square roots of the AVE were greater than the measurement error-adjusted inter-construct correlations deriving from the CFA. The square roots of the AVE for work engagement and supervisor's support were .84 and .74, respectively. Last, the fact that our research outcomes were in line with evidence derived from the extant literature, further strengthened our confidence in the high validity of the collected data.

\section{Results}

The means and standard deviations of the measured variables in Singapore and in the UK are presented in Table 1.

[Insert Table 1 about here]

We performed correlation analysis to assess the relationships among the dependent, independent and control variables (Table 1). To preliminarily assess variations between the two societies, we initially performed an independent samples t-test (Cohen et al., 2013) to explore whether significant differences between employees in Singapore and in the UK were observed. The $\mathrm{t}$-test results $\left(\mathrm{t}_{(428)}=2.06, \mathrm{p}=.04\right)$ indicated that levels of work engagement in Singapore $(\mathrm{M}=$ $5.11, \mathrm{SD}=1.32)$ were significantly different than employee engagement levels in the $\mathrm{UK}(\mathrm{M}=$ $4.89, \mathrm{SD}=.82$ ). A statistically significant difference was also observed with regard to the supervisor's support levels between the two societies. Hypotheses 1, 2, 3 and 4 were tested using hierarchical moderated regression analysis (Cohen et al., 2013), where gender, age, education, 
hierarchical rank, weekly workload, shared parenthood and number of children were treated as control variables. We reviewed the correlation coefficients between the independent variables (Hair et al. 1998) and we evaluated the risk of multicollinearity among the independent variables calculating Tolerance and Variance Inflation Factor (VIF) diagnostics. The VIF values were low (VIF<2.67) for good levels of tolerance (Tolerance>.38) (Tabachnick \& Fidell, 2013).

[Insert Table 2 about here]

The results of the moderated regression analysis on work engagement are presented in Table 2. The first step of the analysis provided a significant regression model $(\mathrm{F}=2.25, \mathrm{p}<.05)$ for the contribution of the control variables to the explanation of work engagement levels. Hierarchical rank $(\beta=.17, \mathrm{p}<.001)$ was positively related to employee levels of work engagement explaining $2.0 \%$ of the dependent variable's total variance. The deriving model of the second step of the hierarchical regression was statistically significant $(\mathrm{F}=4.74, \mathrm{p} \leq .001)$, increasing the explained total variance to $7.0 \%$. Hierarchical rank $(\beta=.15, \mathrm{p}<.001)$ and supervisor's support $(\beta=.24, \mathrm{p}<.001)$ were positively associated with work engagement levels. The third model of the regression analysis, which included the interaction variable (disability severity * supervisor's support), was also significant $(\mathrm{F}=4.78, \mathrm{p}<.001)$, explaining $8.0 \%$ of the dependent variable's total variance. Hierarchical rank $(\beta=.14, \mathrm{p}<.05)$ and supervisor's support $(\beta=.37, \mathrm{p}<.001)$ were positively associated with work engagement levels, whereas the interaction variable $(\beta=-.17, \mathrm{p}<.05)$ was negatively related to work engagement. The fourth model $(\mathrm{F}=5.23, \mathrm{p} \leq .001)$, which included the society variable, explained $10.0 \%$ of the dependent variable's total variance. The coefficients of the hierarchical rank $(\beta=.11, \mathrm{p}<.05)$ and supervisor's support $(\beta=.38, \mathrm{p}<.001)$ variables were positive, whereas the coefficients of the shared parenthood $(\beta=-12, \mathrm{p}<.05)$, interaction (disability severity * supervisor's support) $(\beta=-.17, \mathrm{p}<.05)$ and society $(\beta=-.20, \mathrm{p}<.01)$ variables were negative.

Employees who rank high in the organizational hierarchy, those who do not share parenthood with a partner and those who enjoy higher levels of support by their supervisor tend to display higher levels of work engagement. Moreover, when employee child's disability severity is high, the effect that supervisor's support has on levels of work engagement is significantly stronger than the effect that supervisor's support has on work engagement when employee child's disability severity is low (see Figure 1 for the plot of the interaction). Last, employees in Singapore display higher levels of work engagement than employees in the UK. Based on these findings, hypotheses 1,2 and 4 were corroborated.

[Insert Figure 1 about here]

\section{Discussion}

The analysis of the results indicates that the work engagement levels of employees who are parents of children with SND tend to be dependent on both organizational and family factors in Singapore and the UK. Arguably, support from the supervisor appears to positively impact employees' levels of work engagement. Very importantly, supervisor's support moderates the relationship between employee child's disability severity and employee work engagement. Also, rising hierarchical rank and single parenting are associated with higher levels of work engagement. In addition, societal affiliation explains variations in employees' levels of work engagement.

The comparison between Singapore and the UK contributes to the value of this research, corroborating differences regarding job attitudes of employees living and working in the studied societies, while expanding work engagement research in the Asian region (Shimazu et al., 2010). Our findings demonstrate attitudinal variations between employees in the two samples. The Singaporean employees in our sample reported higher levels of work engagement and lower levels 
of supervisor's support than the UK respondents. This finding aligns with evidence suggested by Triandis and Suh (2002) and others (e.g., Brough et al., 2013; Lu et al., 2006; Schaufeli, 2018) regarding varying employee attitudes in diverse societies. These differences may be attributed to a multitude of factors related to organizational culture and/ or socio-cultural, economic and legal discrepancies among societies (Schaufeli, 2018) as well as to institutional differences. It could also be assumed that the higher levels of work engagement in Singapore could partially be explained by the increased levels of family-based support initiatives (e.g., access to domestic help) that disability caregivers currently receive. This could be an indication that for employees with children with disabilities, the work-based arrangements that are currently in place in the UK need to be further enhanced with family-based arrangements in order to promote these employees' levels of work engagement. Yet, the validation of the role of these factors has not been the objective of the current research and remains to be assessed by future studies. Furthermore, the corroboration of the tested variables' relationships in Singapore and the UK may inform human resource management scholars and practitioners in these two specific societies.

Moreover, this study emphasizes the importance that supervisor's support may have on levels of work engagement of employees who are parents of children with disabilities, a finding that has not been previously empirically investigated. Prior research has tested supervisor's support in general (e.g., Llorens et al., 2006) or in more specific employee samples, such as that of nurses (e.g., Holland et al., 2016; Naruse et al., 2013) or that of teachers (Bakker et al.; 2007, Swanberg et al., 2011). The corroborated hypothesis in a sample of employees who are parents of children with SND generalizes theory in more diverse employee populations, while simultaneously amplifying work engagement literature with respect to disability and diversity management.

Consistent with the perceived organizational support and family-work strain literatures (Eisenberger et al., 2002; Hobfoll, 1989; Thomas \& Ganster, 1995), in this study, we discovered a moderating role that supervisor's support holds in the relationship between employee child's disability severity and work engagement. For employees who have children with more severe disabilities, higher levels of support by their supervisors increases significantly their work engagement levels. Conversely, for employees whose children experience more severe disability types, the role of supportive supervisors in promoting employee work engagement levels is significantly more important than it is for employees whose children experience mild disability types. This finding, which is empirically corroborated for the first time, is in line with existing preliminary empirical evidence regarding the interaction effect of family-work strain and supervisor's support on work engagement (e.g., Zacher \& Winter, 2011), as well as caregiving needs and workplace support on career disruption (Bainbridge \& Broady, 2017). Based on our results, the understanding, sympathy and support expressed by supervisors at the workplace has a more important positive effect on the work engagement of employees with children with more severe disabilities. This finding may benefit perceived organizational support theory, suggesting that family constraints need to be recognized and carefully addressed in the organizational context (e.g., adoption of policies that may attenuate family-work conflict), to allow subordinates to reap the benefits derived from increased levels of supervisors' support.

Albeit a byproduct of our study, hierarchical rank was observed to be positively associated with levels of work engagement. Employees who possess a higher position in the organizational hierarchy present significantly higher levels of engagement. This result regarding rank should be further assessed in combination with other variables, such as supervisor's support. Based on this research's correlations matrix, higher ranked employees tend to work longer hours and to enjoy higher levels of supervisor's support, a factor that is positively associated with work engagement. 
Literature has identified several associations between individual characteristics and work engagement (e.g., Denton et al., 2008), specifically calling for the investigation of the relationship between job status and work engagement (Naruse et al., 2013), an objective that may be the focus of future research efforts.

Last, we identified a negative relationship between shared parenthood and work engagement. Indeed, differences in the work behavior of single and partnered employees who are parents of children with SND have been previously reported in the literature. For instance, Porterfield (2002) refers that single mothers with children with SND are significantly more likely to increase their employment hours than married mothers, possibly due to the increased needs for additional financial resources. Research emphasizes the increased stress levels of single parents with children with high caregiving demands (e.g., Granek, 2012). Taking into consideration that such family demands increase the likelihood of stress symptoms (Cannuscio et al., 2004), we reflect that single parents, who experience high stress levels tend to be more engaged with their work as a way to escape family strain, maintain a positive mindset and invest productive time toward themselves and the society. Hence, these employees may display higher levels of work engagement developing positive perceptions, which, as Hastings and Taunt (2002) suggest, may help them and their families adapt or cope with the stressful experience of raising a child with SND.

\section{Limitations and suggestions for future research}

The design and implementation of this research displays several limitations. First, the data collected in Singapore and the UK through special and mainstream schools from urban areas may not necessarily be indicative of the many different underlying workplace and homeplace dynamics in both societies (Schwarz \& Bohner, 2001). Adopting diversified data collection paths, such as ethnography, future studies may investigate differences that might exist in the attitudes of employees with children with SND and their behavior, both at home and at work. Furthermore, the identification of cross-societal variations may consequently serve as the theoretical basis for the consideration of societal and cultural specificities by future research efforts.

Second, our research investigated the attitudes of employees with children with SND employing a cross-sectional data collection methodology. Although we adopted several procedural and statistical precautions to minimize risks associated with common method bias (Podsakoff et al., 2012), we recognize limitations derived from the fact that our data were collected through singlerespondent self-administered questionnaires. Also, although the participating parents in this study have been provided with detailed diagnoses which specifically describe the disability severity of their children within the school context (i.e., "statements of special needs of their children"), we recognize the self-report nature of the measurement of children's functioning as a limitation of this research. Future research could additionally focus on the collection of qualitative data using interviews, observations and student-specific reports. The use of qualitative methods in the collection of data could provide in-depth justifications and interpretations to explain better the intricacies around the complex social issue of work engagement (e.g. specific supervisory practices that can support employees with children with severe disabilities).

Third, although our research specifically focused on employees whose family strain is associated with their role as parents of children with SND, increased strain may also derive from the parenthood of children without SND. Furthermore, in this research we did not investigate the attitudes of parents with children with SND who left their work due to increased caregiving responsibilities. Thus, future research could comparatively measure attitudinal similarities and differences among these different groups of parents. 
Fourth, this research examined specific relationships that have previously been sporadically investigated in the extant literature (e.g., the impact of supervisor support on work engagement). In this study, we call for further research that could investigate whether the relationships that we observed (e.g., the moderating role of supervisor support) can be replicated in other diverse populations and better explain implications of these relationships for these populations.

Recognizing that there are other factors that could possibly influence work engagement, we, also, encourage future researchers to assess additional variables, such as organizational instrumental support, flexible work arrangements, underemployment or over-qualification, as antecedents of work engagement levels of parents with children with SND.

Last, our results are based on data drawn from Singapore and the UK, and thus the inferred research conclusions are society-specific. Hence, the generalizability of our conclusions about the work engagement of employees with children with SND in other societies may be limited. We consider that future replications of our study in other societies would potentially refine further the employed research framework, while providing more rigorous research conclusions that would stem from divergent organizational, economic, socio-cultural and legal specificities. To this end, the development of more multi-level research designs, such as that of Schreurs et al. (2014), and the adoption of a polycontextual approach (Tsui et al., 2007), could robustly contribute to the explanation of work engagement including both individual-level and society-level (e.g., institutional and cultural) predictors.

\section{Conclusions and implications for practice}

One of the innovative elements of this research has been its emphasis on a largely overlooked population, that of employees who have increased strain at home associated with their roles as parents of children with disabilities. Much of the existing work regarding caregivers of children with disabilities has adopted an Economics or an Industrial Relations perspective. We reflect that the present research fills a significant gap in the literature proposing a research framework for the study of roles and attitudes of these caregivers in their workplaces. Furthermore, the empirical testing of job attitudes among employees who are parents of children with SND, extends the existing literature in a diverse population and, thus, its findings can significantly support the robustness of existing and future research models. Moreover, this research identifies discrepancies in employees' attitudes toward work engagement that may be attributable to a multitude of contextual factors (e.g., home-based versus work-based provisions). Although the explanation of such discrepancies has been beyond the objectives of this study, the cross-societal examination of the measured variables in the Singaporean and UK contexts highlights the need to further validate research tools, identifying antecedents and enriching theories in more societies, especially in regions outside the USA and Europe (Brough et al., 2013), evidently benefiting human resource management scholarship.

At the same time, this research offers several implications for practice. Workforce diversity has been receiving increased attention during the past years, and is expected to grow in the upcoming decades. To enhance diversity, human resource management practitioners are encouraged to consider designing policies that may provide support and accommodations to employees who are parents of children with SND, considering carefully disability severity issues. Due to the lack of officially institutionalized practices, a fact that is acknowledged in several policy documents regarding inclusive work environments (e.g., Children and Family Act, 2014; European Commission, 2010; NCSS, 2016), many employees who have children with SND tend not to report at work their increased parental responsibilities. Highlighting the importance of supervisor's 
support for the family and parental responsibilities of employees with children with SND, this study shows that dependent family members' disability is an element that, if vocalized in the workplace, may contribute actively to positive work psychology. Last, based on the outcomes of this and other studies (e.g. Lu et al., 2006), practitioners should not neglect societal differences whenever assessing employee job variables, such as those of work engagement and perceived supervisor's support. More specifically, the current study's findings imply that, for employees with children with SND, different approaches to human resource management in different societies, or for multinational businesses operating in different countries, could be considered and subsequently adopted.

The results of this study suggest that work engagement is per se an employee-level variable that is clearly dependent on factors both internal and external to the organization. Inside the organizational environment, supervisor's support and hierarchical rank appear to be instrumental toward the development of high work engagement levels. As perceived organizational support literature indicates, higher support may lead to improved employee well-being, which in turn translates into higher organizational commitment and performance, as well as lower turnover (Eisenberger et al., 2002). Also, given the reported positive relationship between hierarchical rank and work engagement, the provision of opportunities to develop and implement a well-defined career path could possibly strengthen employees' levels of work engagement. Although family-work strain literature highlights the positive service that job accommodations provide to employees with requiring roles at home, the present research elucidates that adjusting work-related variables does not suffice. It is, thus, imperative that human resource management executives closely collaborate with employees to aid them in identifying ways to alleviate increased levels of family strain, possibly by providing accommodations related to their children with SND (e.g., flexibility regarding daycare services). Research argues that formal family supportive organizational policies can mitigate the increasing employee family demands through enhanced boundary flexibility (Allen, 2001; Kossek \& Distelberg, 2009). Pointing toward this direction, the results of this study also have important implications for societies that do not possess a legal framework for the workplace and/ or home-based support of parents of children with SND, providing a robust rationale why developing corresponding policies can be unilaterally advantageous.

\section{Acknowledgement}

The authors would like to thank three anonymous reviewers for their insightful comments and an anonymous editor who directed them in refining this manuscript.

\section{References}

Alfes, K., Truss, C., Soane, E. C., Rees, C., \& Gatenby, M. (2013). The relationship between line manager behavior, perceived HRM practices, and individual performance: Examining the mediating role of engagement. Human resource management, 52, 839-859.

Allard, K., Haas, L., \& Hwang, C. P. (2011). Family-Supportive organizational culture and fathers' experiences of work-Family conflict in Sweden. Gender, Work \& Organization, 18, 141-157.

Allen, M. J., \& Yen, W. M. (2001). Introduction to measurement theory. New York: Waveland.

Amstad, F. T., Meier, L. L., Fasel, U., Elfering, A., \& Semmer, N. K. (2011). A meta-analysis of work-family conflict and various outcomes with a special emphasis on cross-domain versus matching-domain relations. Journal of Occupational Health Psychology, 16, 151-169.

Bainbridge, H.T., \& Broady, T. R. (2017). Caregiving responsibilities for a child, spouse or parent: The impact of care recipient independence on employee well-being. Journal of Vocational Behavior, 101, 57-66.Bagger, J., \& Li, A. (2012). Being important matters: The impact of work 
and family centralities on the family-to-work conflict-satisfaction relationship. Human Relations, 65, 473-500.

Bagozzi, R. P., \& Yi, Y. (1988). On the evaluation of structural equation models. Journal of The Academy of Marketing Science, 16, 74-94.

Bainbridge, H. T., \& Broady, T. R. (2017). Caregiving responsibilities for a child, spouse or parent: The impact of care recipient independence on employee well-being. Journal of Vocational Behavior, 101, 57-66.

Bakker, A. B. (2014). Daily fluctuations in work engagement. European Psychologist, 19, 227-236.

Bakker, A. B., \& Demerouti, E. (2007). The job demands-resources model: State of the art. Journal of Managerial Psychology, 22, 309-328.

Bakker, A. B., \& Demerouti, E. (2008). Towards a model of work engagement. Career Development International, 13, 209-223.

Bakker, A. B., Demerouti, E., Taris, T., Schaufeli, W. B., \& Schreurs, P. (2003). A multi-group analysis of the Job Demands-Resources model in four home care organizations. International Journal of Stress Management, 10, 16-38.

Bakker, A. B., Hakanen, J. J., Demerouti, E., \& Xanthopoulou, D. (2007). Job resources boost work engagement, particularly when job demands are high. Journal of Educational Psychology, 99, 274-284.

Behson, S. J. (2002). Coping with family-to-work conflict: The role of informal work accommodations to family. Journal of Occupational Health Psychology, 7, 324-341.

BIS. (2011a). Extending the right to Request Flexible Working to All: Impact Assessment. www.gov.uk, Accessed August. 10, 2019.

BIS. (2011b). Flexible Parental Leave: Impact Assessment. www.gov.uk, Accessed May. 10, 2018.

Bittman, M., Hill, T., \& Thomson, C. (2007). The impact of caring on informal careers, employment, income and earnings: A longitudinal approach. Australian Journal of Social Issues, 42, 255-272.

Booth, C. L., \& Kelly, J. F. (1998). Child-care characteristics of infants with and without special needs: Comparisons and concerns. Early Childhood Research Quarterly, 13, 603-621.

Brannan, A. M., Brennan, E. M., Sellmaier, C., \& Rosenzweig, J. M. (2018). Employed parents of children receiving mental health services: Caregiver strain and work-life integration. Families in Society: Journal of Contemporary Social Services, 99(1), 29-44.

Breevaart, K., \& Bakker, A. B. (2011). Working parents of children with behavioral problems: a study on the family-work interface. Anxiety, Stress, \& Coping, 24, 239-253.

Brennan, E. M., \& Brannan, A. M. (2005). Participation in the paid labor force by caregivers of children with emotional and behavioral disorders. Journal of Emotional and Behavioral Disorders, 13, 237-246.

Brough, P., Timms, C., Siu, O. L., Kalliath, T., O’Driscoll, M. P., Sit, C. H., ... \& Lu, C. Q. (2013). Validation of the Job Demands-Resources model in cross-national samples: Cross-sectional and longitudinal predictions of psychological strain and work engagement. Human Relations, 66, 1311-1335.

Brown, T. J., \& Clark, C. (2017). Employed parents of children with disabilities and work family life balance: A literature review. Child \& Youth Care Forum, 46, 857-876.

Buckner.L \& Yeandle, C. (2006). Managing More than Most: A statistical analysis of families with sick or disabled children. https://contact.org.uk/media/381150/caringforsickanddisabledchildren2006appendix.pdf, Accessed August. 10, 2019. 
Carmichael, F., \& Charles, S. (2003). The opportunity costs of informal care: does gender matter? Journal of Health Economics, 22(5), 781-803.

Cheung, G. W. \& Rensvold, R. B. (2002). Evaluating goodness-of-fit indexes for testing measurement invariance. Structural Equation Modeling, 9, 233-255.

Children and Families Act. (2014). Part 7-9. www.legislation.gov.uk, Accessed February. 27, 2019.

CIA. The world factbook. www.cia.gov, Accessed August. 10, 2019.

Cohen, J., Cohen, P., West, S. G., \& Aiken, L. S. (2013). Applied multiple regression/correlation analysis for the behavioral sciences. New York: Routledge.

CONTACT for families with disabled children. (2018). Caring more than most. https://contact.org.uk/news-and-blogs/a-quarter-of-uk-parents-of-disabled-children-provide-100hours-of-care-a-week-new-research-launched-today/ Accessed August. 10, 2019.

Conway, J. M., \& Lance, C. E. (2010). What reviewers should expect from authors regarding common method bias in organizational research. Journal of Business and Psychology, 25, 325334.

Deci, E. L., Ryan, R. M., Gagné, M., Leone, D. R., Usunov, J., \& Kornazheva, B. P. (2001). Need satisfaction, motivation, and well-being in the work organizations of a former eastern bloc country: A cross-cultural study of self-determination. Personality and Social Psychology Bulletin, 27, 930-942.

Demerouti, E., Bakker, A. B., Nachreiner, F. \& Schaufeli, W. B. (2001). The job demandsresources model of burnout. Journal of Applied Psychology, 86, 499-512.

Denton, D. A., Newton, J. T., \& Bower, E. J. (2008). Occupational burnout and work engagement: a national survey of dentists in the United Kingdom. British Dental Journal, 205, 1-8.

DfE (Department of Education). 2018. Special educational needs in England. National statistics. https://assets.publishing.service.gov.uk/government/uploads/system/uploads/attachment_data/fil e/729208/SEN_2018_Text.pdf. Accessed August. 10, 2019.

Dillon-Wallace, J. A., McDonagh, S. H., \& Fordham, L. A. (2016). Maternal employment, work experiences, and financial well-being of Australian mothers who care for young children with special health care needs. Journal of Family Issues, 37, 299-320.

Economist Intelligence Unit. (2017). Democracy Index 2017. www.eiu.com, Accessed May. 10, 2018.

Eisenberger, R., Huntington, R., Hutchison, S., \& Sowa, D. (1986). Perceived organizational support. Journal of Applied Psychology, 71, 500-507.

Eisenberger R, Singlhamber F, Vandenberghe C, Sucharski I, Rhoades L. (2002). Perceived supervisor support: Contributions to perceived support and employee retention. Journal of Applied Psychology, 87, 565-573.

European Commission. (2010). European Disability Strategy 2010-2020: A Renewed Commitment to a Barrier-Free Europe. www.eur-lex.europa.eu, Accessed May. 10, 2019.

Farndale, E., \& Murrer, I. (2015). Job resources and employee engagement: a cross-national study. Journal of Managerial Psychology, 30, 610-626.

Fetton, E. \& Mearns, J. (2012). Finding Flexibility: Parents of Disabled Children and Paid Work, A Working Families Publication. www.workingfamilies.org.uk, Accessed May, 10, 2019.

Flade, P. (2003). Great Britain's workforce lacks inspiration. Gallup Management Journal, 11 December, 7-10. www.jwalkonline.org, Accessed May. 10, 2019.

Ford, M. T., Heinen, B. A., \& Langkamer, K. L. (2007). Work and family satisfaction and conflict: A meta-analysis of cross-domain relations. Journal of Applied Psychology, 92, 57-80. 
Fornell, C., \& Larcker, D. F. (1981). Evaluating structural equation models with unobservable variables and measurement error. Journal of Marketing Research, 18, 39-50.

Frye, N. K. \& Breaugh, J. A. (2004). Family-friendly policies, supervisor support, work-family conflict, family-work conflict, and satisfaction: a test of a conceptual model, Journal of Business and Psychology, 19, 2197-220.

Grandey, A. A., \& Cropanzano, R. (1999). The conservation of resources model applied to workfamily conflict and strain. Journal of Vocational Behavior, 54, 350-370.

Granek, L., Rosenberg-Yunger, Z. R. S., Dix, D., Klaassen, R. J., Sung, L., Cairney, J., \& Klassen, A. F. (2014). Caregiving, single parents and cumulative stresses when caring for a child with cancer, Child: care, health and development, 40, 184-194.

Greenhaus, J. H., \& Beutell, N. J. (1985). Sources of conflict between work and family roles. Academy of Management Review, 10, 76-88.

Hair, J. F., Anderson, R. E., Tatham, R. L., \& Black, W. C. (1998). Multivariate Data Analysis, Upper Saddle River: Prentice Hall.

Hermanns, M., \& Mastel-Smith, B. (2012). Caregiving: A qualitative concept analysis. The Qualitative Report, 17(38), 1-18.

Hobfoll, S. E. (1989). Conservation of resources: A new attempt at conceptualizing stress. American psychologist, 44, 513-524.

Hofstede, G. (2017). Hofstede Insights. Retrieved from: https://www.hofstede-insights.com, Accessed May 10, 2019.

Holland, P., Cooper, B., \& Sheehan, C. (2017). Employee voice, supervisor support, and engagement: The mediating role of trust. Human Resource Management, 56, 915-929.

House, R. J., Hanges, P. J., Javidan, M., Dorfman, P. W., \& Gupta, V. (2004). Culture, leadership and organizations: The GLOBE study in 62 societies. Thousand Oaks, CA: Sage.

Hu, L., \& Bentler, P. M. (1999). Cutoff criteria for fit indexes in covariance structure analysis: Conventional criteria versus new alternatives. Structural Equation Modeling, 6, 1-55.

International Labour Organization Department of Statistics (2019). Statistics on labour productivity. Retrieved from: https://www. https://ilostat.ilo.org/, Accessed June 3, 2020.

James, J., McKechnie, S. P., \& Swanberg, J. (2011). Predicting employee engagement in an agediverse retail workforce. Journal of Organizational Behavior, 32, 173-196.

Karatepe, O. M., \& Olugbade, O. A. (2009). The effects of job and personal resources on hotel employees' work engagement. International Journal of Hospitality Management, 28, 504-512.

Kossek, E., \& Distelberg, B. (2009). Work and family employment policy for a transformed work force: Current trends and themes. In A Crouter \& A Booth (Eds.), Work-life Policies (pp. 3-49). Washington, DC: Urban Institute Press.

Kossek, E., Lewis, S., \& Hammer, L. B. (2010). Work-life initiatives and organizational change: Overcoming mixed messages to move from the margin to the mainstream. Human Relations, 63, 3-19.

Kossek, E. E., Pichler, S., Bodner, T., Hammer, L. B. (2011). Workplace social support and workfamily conflict: A meta-analysis, clarifying the influence of general and work-family-specific supervisor and organizational support. Personnel Psychology, 64, 289-313.

Kulik, C. T., Cregan, C., \& Bainbridge, H. T. (2013). I feel your pain: The moderating effect of care recipient health on the relationship between work hours and care recipient and caregiver psychological outcomes. Analyses of Social Issues and Public Policy, 13, 114-136. 
Kwon, B., Farndale, E., \& Park, J. G. (2016). Employee Voice and Work Engagement: Macro, Meso and Micro-level Drivers of Convergence? Human Resource Management Review, 26, 327-337.

Lai, Y., Saridakis, G., \& Blackburn, R. (2015). Job stress in the United Kingdom: Are small and medium-sized enterprises and large enterprises Different? Stress and Health, 31, 222-235.

Lambe, L. (2012). Supporting families. In P. Lacey and C. Ouvry. (Eds.). People with profound and multiple disabilities: A collaborative approach to meeting complex needs (pp. 167-175). London, David Fulton.

Lee, J.A., Walker, M., Shoup, R. (2001). Balancing elder care responsibilities and work: The impact on emotional health. Journal of Business and Psychology, 16, 277-289.

Lewis, S., Kagan, C., \& Heaton, P. (2000), Managing work-family diversity for parents of disabled children-Beyond policy to practice and partnership, Personnel Review, 29, 417-430.

Li, A., Shaffer, J., \& Bagger, J. (2015). The psychological well-being of disability caregivers: Examining the roles of family strain, family-to-work conflict, and perceived supervisor support. Journal of Occupational Health Psychology, 20, 40-49.

Li, L., Zhong, J. A., Chen, Y., Xie, Y., \& Mao, S. (2014). Moderating effects of proactive personality on factors influencing work engagement based on the job demands-resources model. Social Behavior and Personality: An International Journal, 42, 7-15.

Lien Foundation. (2016). Inclusive Attitudes Survey. www.lienfoundation.org, Accessed May. 10, 2019

Llorens, S., Bakker, A. B., Schaufeli, W., \& Salanova, M. (2006). Testing the robustness of the job demands-resources model. International Journal of Stress Management, 13, 378-391.

Lu, L., Gilmour, R., Kao, S. F. and Huang, M.T. (2006). A cross-cultural study of work/family demands, work/family conflict and wellbeing: the Taiwanese vs British. Career Development International, 11, 9-27.

Mansour, S., \& Tremblay, D. G. (2016). Workload, generic and work-family specific social supports and job stress: Mediating role of work-family and family-work conflict. International Journal of Contemporary Hospitality Management, 28, 1778-1804.

Matthews, R. A., Booth, S. M., Taylor, C. F., \& Martin, T. (2011). A qualitative examination of the work-family interface: Parents of children with autism spectrum disorder. Journal of Vocational Behavior, 79, 625-639.

Ministry of Manpower (2016). MOM survey Conditions of employment Singapore 2016. file://C:/Users/user/Desktop/Disability\%20Statistics\%20for\%20introduction/MOM\%20survey \%20Conditions\%20of\%20employment\%20Singapore\%202016.pdf Accessed August. 10, 2019.

Moreau, E., \& Mageau, G. A. (2012). The importance of perceived autonomy support for the psychological health and work satisfaction of health professionals: Not only supervisors count, colleagues too! Motivation and Emotion, 36, 268-286.

Morris, L. A. (2014). The impact of work on the mental health of parents of children with Disabilities, Family Relations, 63,101-121.

Muthén, L. K., \& Muthén, B. O. (2017). Mplus Version 8 user's guide. Los Angeles, CA: Muthén \& Muthén.

Naruse, T., Sakai, M., Watai, I., Taguchi, A., Kuwahara, Y., Nagata, S., \& Murashima, S. (2013). Individual and organizational factors related to work engagement among home-visiting nurses in Japan. Japan Journal of Nursing Science, 10, 267-272.

NCSS. (2012). 2nd Enabling Masterplan 2012-2016. www.msf.gov.sg, Accessed February. 27 , 2019. 
NCSS. (2016). 3rd Enabling Masterplan 2017-2021. Caring Nation-Inclusive Society. https://sustainabledevelopment.un.org/content/documents/1533Enabling_Masterplan_2017_202 1.pdf Accessed August. 10, 2019.

Neal, M. B., \& Hammer, L. B. (2009). Dual-earner couples in the sandwiched generation: Effects of coping strategies over time. The Psychologist-Manager Journal, 12, 205-234

Netemeyer, R. G., Boles, J., \& McMurrian, R. 1996. Development and validation of work- family conflict scales. Journal of Applied Psychology, 81, 400-409.

Pas, B., Eisinga, R., \& Doorewaard, H. (2016). Predicting medical specialists' working (long) hours: testing a contemporary career model. The International Journal of Human Resource Management, 27, 1730-1754.

Parish, S. L., \& Cloud, J. M. (2006). Financial well-being of young children with disabilities and their families. Social Work, 51, 223-232.

Podsakoff, P. M., MacKenzie, S. B., Lee, J. Y., \& Podsakoff, N. P. (2003). Common method biases in behavioral research: a critical review of the literature and recommended remedies. Journal of Applied Psychology, 88, 879-903.

Podsakoff, P. M., MacKenzie, S. B., \& Podsakoff, N. P. (2012). Sources of method bias in social science research and recommendations on how to control it. Annual Review of Psychology, 65, 539-569.

Podsakoff, P. M., \& Organ, D. W. (1986). Self-reports in organizational research: Problems and prospects. Journal of Management, 12, 531-544.

Poon, K. K. (2013). Parental expectations regarding postschool social attainments of adolescents with autism spectrum disorders in Singapore. American journal on intellectual and developmental disabilities, 118, 95-107.

Porterfield, S. L. (2002). Work choices of mothers in families with children with disabilities. Journal of Marriage and Family, 64, 972-981.

Qing, G., \& Zhou, E. (2017). Bidirectional work-family enrichment mediates the relationship between family-supportive supervisor behaviors and work engagement. Social Behavior and Personality: An International Journal, 45, 299-308.

Rofcanin, Y., Las Heras, M., \& Bakker, A. B. (2017). Family supportive supervisor behaviors and organizational culture: Effects on work engagement and performance. Journal of Occupational health Psychology, 22, 207-217.

Rousseau, V., \& Aube, C. (2010). Social Support at Work and Affective Commitment to the Organization: The Moderating Effect of Job Resource Adequacy and Ambient Conditions. The Journal of Social Psychology, 150, 321-340.

Rosenzweig, J. M., Brennan, E. M., \& Ogilvie, A. M. (2002). Work-family fit: Voices of parents of children with emotional and behavioral disorders. Social Work, 47, 415-424.

Saks, A. M. (2006). Antecedents and consequences of employee engagement. Journal of Managerial Psychology, 21, 600-619.

Schaufeli, W. B. (2018). Work engagement in Europe: Relations with national economy governance and culture, Organizational Dynamics. Advance online publication.

Schaufeli, W., Bakker, A., \& Salanova, M. (2006). The Measurement of Work Engagement with a Short Questionnaire: A Cross-National Study. Educational and Psychological Measurement, 66, 701-716.

Schaufeli, W. B., \& Salanova, M. (2008). Enhancing work engagement through the management of human resources. In K. Naswall, J. Hellgren, \& M. Sverke (Eds.). The Individual in the changing working life (pp. 380-390). New York: Cambridge University Press. 
Schaufeli, W. B., Salanova, M., González-Romá, V., \& Bakker, A. B. (2002). The measurement of engagement and burnout: A two sample confirmatory factor analytic approach. Journal of Happiness Studies, 3, 71-92.

Schieman, S., \& Young, M. (2011). Economic hardship and family-to-work conflict: The importance of gender and work conditions. Journal of Family and Economic Issues, 32, 46-61.

Schwarz, N., \& Bohner, G. (2001). The Construction of Attitudes. In A. Tesser, \& N. Schwarts (Eds.). Blackwell handbook of social psychology: Intraindividual processes (pp. 436-457). Massachusetts: Blackwell Publishers.

Shimazu, A., Schaufeli, W. B., Miyanaka, D., \& Iwata, N. (2010). Why Japanese workers show low work engagement: An item response theory analysis of the Utrecht Work Engagement scale. BioPsychoSocial Medicine, 4, 2-6.

Shockley, K. M., \& Singla, N. (2011). Reconsidering work-family interactions and satisfaction: A meta-analysis. Journal of Management, 37, 861-886.

Singelis, T. M., Triandis, H. C., Bhawuk, D. P., \& Gelfand, M. J. (1995). Horizontal and vertical dimensions of individualism and collectivism: A theoretical and measurement refinement. Cross-Cultural Research, 29, 240-275.

Stefanidis, A., Banai, M., \& Richter, U. H. (2013). Employee attitudes toward questionable negotiation tactics: Empirical evidence from Peru. International Journal of Human Resource Management, 24, 826-852.

Stewart, L. M. (2013). Family care responsibilities and employment: Exploring the impact of type of family care on work-family and family-work conflict. Journal of Family Issues, 34, 113-138.

Swanberg, J. E., McKechnie, S. P., Ojha, M. U., \& James, J. B. (2011). Schedule control, supervisor support and work engagement: A winning combination for workers in hourly jobs? Journal of Vocational Behavior, 79, 613-624.

Swanson, V., \& Power, K. (2001). Employees' perceptions of organizational restructuring: The role of social support. Work and Stress, 15, 161-178.

Tabachnick, B. G., \& Fidell, L. S. (2013). Using multivariate statistics, 6th ed. Boston: Pearson.

Ten Brummelhuis, L. L., \& Bakker, A. B. (2012). A resource perspective on the work-home interface: The work-home resources model. American Psychologist, 67, 545-556.

Ten Brummelhuis, L. L., Haar, J. M., \& Roche, M. (2014). Does family life help to be a better leader? A closer look at crossover processes from leaders to followers. Personnel Psychology, 67, 917-949.

Thomas, L. T., \& Ganster, D. C. (1995). Impact of family-supportive work variables on workfamily conflict and strain: A control perspective. Journal of Applied Psychology, 80, 6-15.

Triandis, H. C., \& Suh, E. M. (2002). Cultural influences on personality. Annual Review in Psychology, 53, 133-160.

Tsui, A.S., Nifadkar, S.S. and Ou, A.Y., 2007. Cross-national, cross-cultural organizational behavior research: Advances, gaps, and recommendations. Journal of Management, 33(3), 426478.

Warfield, M. E. (2001). Employment, parenting, and well-being among mothers of children with disabilities. Mental Retardation, 39(4), 297-309.

Warfield, M. E. (2005). Family and work predictors of parenting role stress among two-earner families of children with disabilities. Infant and Child Development, 14, 155-176.

White, M., Hill, S., McGovern, P., Mills, C., \& Smeaton, D. (2003). High-performance Management Practices, Working Hours and Work-Life Balance. British Journal of Industrial Relations, 41, 175-195. 
Working Families and Unum. (2018). 2018 Off Balance-parents of disabled children and paid work. https://www.workingfamilies.org.uk/publications/off-balance-2018/ Accessed January 27, 2020.

Working Families. (2019). From child to adult disability, transition and family finance. https://www.workingfamilies.org.uk/publications/from-child-to-adult/ Accessed February 27, 2019.

World Bank.Worldwide Governance Indicators. www.datacatalog.worldbank.org, Accessed February 27, 2019.

World Health Organization. (2001). International classification of functioning, disability and health: ICF. Geneva: World Health Organization.

Wright, A., Crettenden, A., \& Skinner, N. (2016). Dads care too! Participation in paid employment and experiences of workplace flexibility for Australian fathers caring for children and young adults with disabilities. Community, Work \& Family, 19, 340-361.

Yang, S., Meredith, P., \& Khan, A. (2015). Stress and burnout among healthcare professionals working in a mental health setting in Singapore. Asian Journal of Psychiatry, 15, 15-20.

Zacher, H., \& Winter, G. (2011). Eldercare demands, strain, and work engagement: The moderating role of perceived organizational support. Journal of Vocational Behavior, 79, 667-680.

Zhang, L., Deng, Y., Zhang, X., \& Hu, E. (2016). Why do Chinese employees build supervisorsubordinate guanxi? A motivational analysis. Asia Pacific Journal of Management, 33, 617-648.

Zhang, Y., \& Liao, Z. (2015). Consequences of abusive supervision: A meta-analytic review. Asia Pacific Journal of Management, 32, 959-987. 
Table 1. Descriptive statistics and correlations matrix of the examined variables

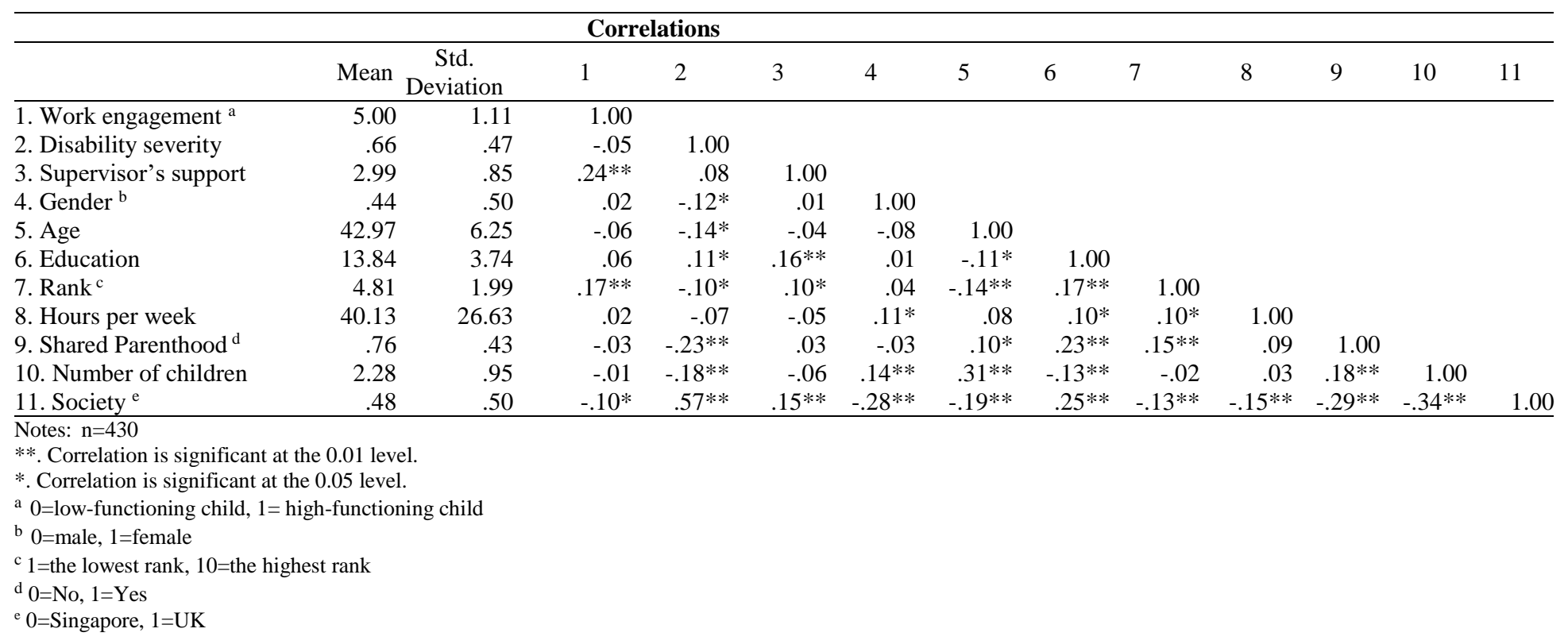

Table 2. Hierarchical Regression Analysis on levels of work engagement 


\begin{tabular}{|c|c|c|c|c|c|c|c|c|}
\hline \multirow[b]{2}{*}{ VARIABLE } & \multicolumn{2}{|c|}{ MODEL 1} & \multicolumn{2}{|c|}{ MODEL 2} & \multicolumn{2}{|c|}{ MODEL 3} & \multicolumn{2}{|c|}{ MODEL 4} \\
\hline & $\beta$ & $\mathrm{t}$ & $\beta$ & $\mathrm{t}$ & $\beta$ & $\mathrm{t}$ & $\beta$ & $\mathrm{t}$ \\
\hline Gender & .00 & .04 & -.01 & -.23 & -.01 & -.26 & -.05 & -.1 .09 \\
\hline $\operatorname{Age}^{a}$ & -.04 & -.67 & -.04 & -.84 & -.04 & -.83 & -.05 & -1.07 \\
\hline Education & .04 & .81 & .02 & .35 & .02 & .48 & .07 & 1.37 \\
\hline Hierarchical rank ${ }^{\mathrm{b}}$ & $.17 * * *$ & 3.45 & $.15 * *$ & 3.01 & $.14 * *$ & 2.79 & $.11^{*}$ & 2.35 \\
\hline Work hours per week & .02 & .39 & .03 & .67 & .04 & .82 & .02 & .43 \\
\hline Shared parenthood ${ }^{c}$ & -.06 & -1.25 & -.08 & -1.59 & -.08 & -1.63 & $-.12 *$ & -2.34 \\
\hline Number of children & .02 & .43 & .03 & .52 & .02 & .37 & -.01 & -.16 \\
\hline Disability severity ${ }^{d}$ & & & -.08 & -1.51 & -.08 & -1.67 & .00 & -.00 \\
\hline Supervisor's support (SS) & & & $.24 * * *$ & 4.96 & $.37 * * *$ & 4.82 & $.38 * * *$ & 4.97 \\
\hline Disability severity x SS & & & & & $-.17 *$ & -2.20 & $-.16^{*}$ & -2.09 \\
\hline Society ${ }^{\mathrm{e}}$ & & & & & & & $-.20 * *$ & -2.96 \\
\hline $\mathrm{R}^{2}$ & & $.04 *$ & & $.09 * * *$ & & $.10^{* * *}$ & & $.12 * * *$ \\
\hline Adj. $\mathrm{R}^{2}$ & & $.02 *$ & & $.07 * * *$ & & $.08^{* * *}$ & & $.10 * * *$ \\
\hline$\Delta \mathrm{R}^{2}$ & & - & & $.05 * * *$ & & $.01 * * *$ & & $.02 * * *$ \\
\hline F-statistic & & $2.25^{*}$ & & $4.74 * * *$ & & $4.78 * * *$ & & $5.23 * * *$ \\
\hline
\end{tabular}

Notes: $\mathrm{n}=430$; standardized regression coefficients are reported.

$* \mathrm{p}<.05 * * \mathrm{p}<.01 * * * \mathrm{p}<.001$

${ }^{\mathrm{a}} 0=$ male, $1=$ female; ${ }^{\mathrm{b}} 1=$ the lowest rank, $10=$ the highest rank;

${ }^{\mathrm{c}} 0=\mathrm{No}, 1=$ Yes

${ }^{\mathrm{d}} 0=$ low-functioning child, $1=$ high-functioning child

${ }^{\mathrm{e}} 0=$ Singapore, $1=\mathrm{UK}$

Figure 1. The moderating effect of child's disability severity on the relationship between supervisor's support and work engagement 


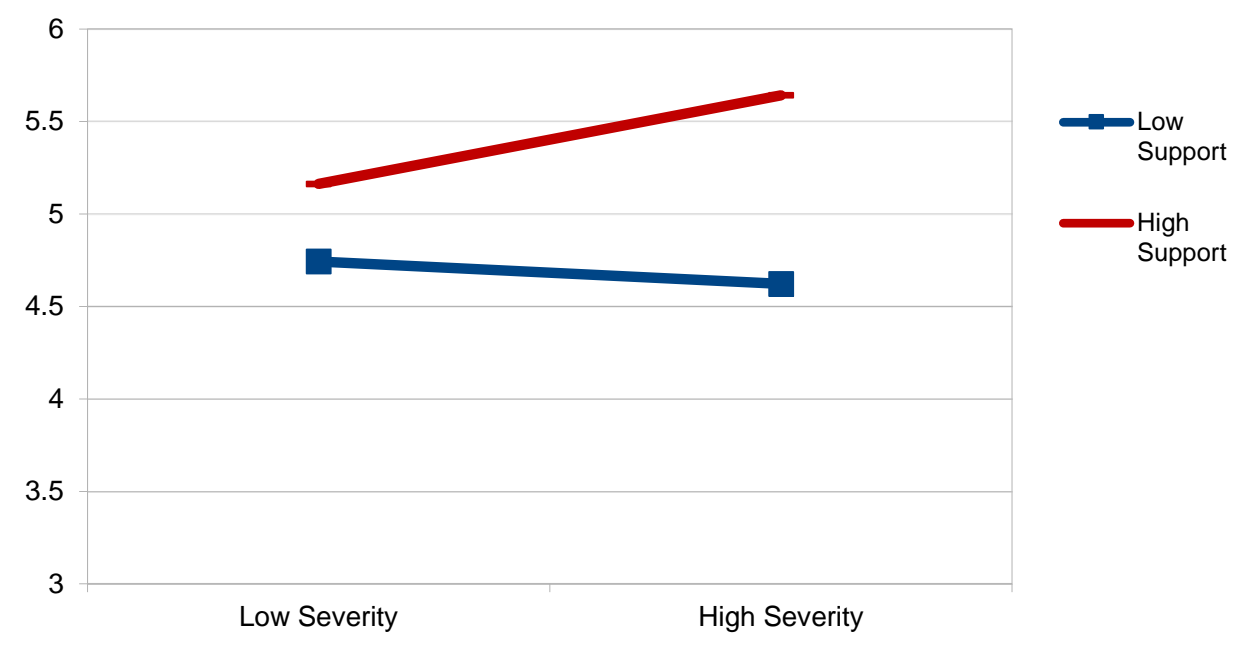

